\section{IMPACT OF INITIAL FLUSH POTASSIUM CONCENTRATION ON THE ADEQUACY OF LUNG PRESERVATION}

The effects of initial lung flushing with intracellular and extracellular fluid type solutions were studied in lungs stored with the University of Wisconsin solution. Excised Sprague-Dawley rat lungs $(n=39)$ were flushed first with one of the following solutions: (1) the University of Wisconsin solution $\left(\mathrm{K}^{+}=140 \mathrm{mmol} / \mathrm{L}\right)$, (2) modified (low potassium) University of Wisconsin solution $\left(\mathrm{K}^{+}=20 \mathrm{mmol} / \mathrm{L}\right)$, (3) phosphate buffered saline solution $\left(K^{+}=3.9 \mathrm{mmol} / \mathrm{L}\right)$, (4) modified low-potassium phosphate-buffered saline solution $\left(\mathrm{K}^{+}=20 \mathrm{mmol} / \mathrm{L}\right)$, (5) modified high-potassium phosphate-buffered saline solution $\left(\mathrm{K}^{+}=\mathbf{4 0} \mathrm{mmol} / \mathrm{L}\right)$, and (6) Euro-Collins solution $\left(\mathrm{K}^{+}=115 \mathrm{mmol} / \mathrm{L}\right)$ followed by secondary flush with storage solution and cold $\left(4^{\circ} \mathrm{C}\right)$ storage in University of Wisconsin solution for 24 hours. The lungs were then reperfused in the isolated, pulsatile, blood-perfused working lung system for 2 hours or until lung failure. Blood gas analysis and shunt fraction, aerodynamic parameters (airway resistance, lung compliance, elastic work, and flow resistive work), and total pulmonary vascular resistance were measured throughout the perfusion period. The mean oxygen tensions (in millimeters of mercury) at $\mathbf{3 0}$ minutes after the onset of reperfusion for University of Wisconsin solution, modified University of Wisconsin solution, phosphate-buffered saline solution, modified phosphate-buffered saline solutions (20 and $40 \mathrm{mmol} / \mathrm{L}$ ), and Euro-Collins solution were $56.1 \pm 4.2,72.7 \pm 9.1,87.7 \pm 6.9$ ( $p<0.01$ versus University of Wisconsin solution; $p<0.01$ versus Euro-Collins solution), $86.0 \pm 9.6$ ( $p<0.01$ versus University of Wisconsin solution; $p<0.01$ versus Euro-Collins solution), $87.9 \pm 7.7$ ( $p<0.01$ versus University of Wisconsin solution; $p<0.01$ versus Euro-Collins solution), and $53.5 \pm 6.0$, respectively. All aerodynamic parameters in the lungs flushed with extracellular fluid type solutions were superior to those flushed with intracellular fluid type solutions. We conclude that the efficacy of initial flushing was essential for successful lung preservation and that extracellular fluid type solutions were superior to intracellular fluid type solutions, at least for flushing the lung before storage with University of Wisconsin solution. Potassium concentration in flushing solution should be $20 \mathrm{mmol} / \mathrm{L}$ or less to obtain appropriate flushing and subsequent adequate distribution of the storage solution. (J Thorac Cardiovasc Surg 1995;109:1090-6)

Shigeyuki Sasaki, MD, PhD (by invitation), James D. McCully, $\mathrm{PhD}$ (by invitation), Francesca Alessandrini, BS (by invitation), and Joseph LoCicero III, MD, FACS, Boston, Mass.
In the current standard procedures for lung transplantation, Euro-Collins solution (ECS) and the University of Wisconsin solution (UWS) are widely

\footnotetext{
From the Division of Cardiothoracic Surgery, New England Deaconess Hospital, Harvard Medical School, Boston, Mass.

Read at the Seventy-fourth Annual Meeting of The American Association for Thoracic Surgery, New York, N.Y., April 24-27, 1994.

Address for reprints: Joseph LoCicero III, MD, Chief, Division of General Thoracic Surgery, New England Deaconess Hospital, Harvard Medical School, 110 Francis St., No. 2C, Boston, MA 02215.

Copyright (c) 1995 by Mosby-Year Book, Inc.

$0022-5223 / 95 \$ 3.00+0 \quad \mathbf{1 2 / 6 / 6 3 2 0 6}$
}

used for the flushing and storage of the lung graft., 1,2 The two solutions have similar electrolyte compositions of the intracellular fluid type, with low sodium and high potassium concentrations. However, solutions with high potassium concentration have been reported to cause severe vasoconstriction., 4 They would be unsuitable for flushing the lung graft because vasoconstriction would produce poor distribution of the perfusate. The recent development of extracellular fluid type solutions for lung preservation, ${ }^{5-10}$ such as low-potassium dextran solution or low-potassium UWS, provides the possibility of extended lung preservation, but intracellular fluid type solution is still believed to be beneficial for organ storage. 1,2 
Table I. Composition of colloidal flushing solutions

\begin{tabular}{|c|c|c|}
\hline & $U W S$ & $m U W S$ \\
\hline Hydroxyethyl starch $(\mathrm{gm} / \mathrm{L})$ & 50 & 50 \\
\hline Lactobionic acid (mmol/L) & 100 & 100 \\
\hline Raffinose $(\mathrm{mmol} / \mathrm{L})$ & 30 & 30 \\
\hline Adenosine $(\mathrm{mmol} / \mathrm{L})$ & 5 & 5 \\
\hline Allopurinol (mmol/L) & 1 & 1 \\
\hline Glutathione (mmol/L) & 3 & 3 \\
\hline $\mathrm{KH}_{2} \mathrm{PO}_{4}(\mathrm{mmol} / \mathrm{L})$ & 25 & 20 \\
\hline $\mathrm{NaH}_{2} \mathrm{PO}_{4}(\mathrm{mmol} / \mathrm{L})$ & & 5 \\
\hline $\mathrm{MgSO}_{4}(\mathrm{mmol} / \mathrm{L})$ & 5 & 5 \\
\hline $\mathrm{KOH}(\mathrm{mmol} / \mathrm{L})$ & 115 & \\
\hline $\mathrm{NaOH}(\mathrm{mmol} / \mathrm{L})$ & 20 & 135 \\
\hline Total $\mathrm{Na}^{+}(\mathrm{mmol} / \mathrm{L})$ & 20 & 140 \\
\hline Total $\mathrm{K}^{+}(\mathrm{mmol} / \mathrm{L})$ & 140 & 20 \\
\hline $\mathrm{pH}$ & 7.4 & 7.4 \\
\hline Osmolarity (mOsm) & 320 & 320 \\
\hline
\end{tabular}

Previous studies in which extracellular fluid type solutions were compared with intracellular type solutions for lung preservation used the same solution for both flushing and storage..$^{5-8,10}$ Yamazaki and associates, ${ }^{9}$ studying flushing and storage solutions, demonstrated high vascular resistance in lungs initially flushed with high-potassium solutions. They postulated that this was a direct effect of high potassium concentration but did not determine the pharmacologic threshold of this effect. We postulated that the two procedures of flushing and storage should be investigated separately, inasmuch as they might have different purposes. An important role of initial flushing in lung preservation is the removal of blood from the pulmonary vascular bed, which otherwise would impair lung function after storage by plugging the vessels, preventing the tissue from cooling, and allowing for membranous damage by macrophages and neutrophils that would remain during preservation. ${ }^{11,12}$ We presumed that the superiority of extracellular over intracellular fluid type solutions recently demonstrated was mostly due to better flushing, and we focused on the flushing procedure in this study. The purpose of this study was to investigate separately the effect of flushing with different types of solutions, followed by standard procedures for lung storage, and to determine the ultimate composition of the flushing solution for lung preservation.

\section{Materials and methods}

Male Sprague-Dawley rats weighing 325 to $350 \mathrm{gm}$ were obtained from Taconic Farms (Germantown, N.Y.) and were allowed free access to food and water. Housing and
Table II. Composition of crystalloid flushing solutions

\begin{tabular}{lcccc}
\hline & $D P B S$ & $m P B S 1$ & $m P B S 2$ & $E C$ \\
\hline $\mathrm{NaCl}(\mathrm{mmol} / \mathrm{L})$ & 138 & 124 & 104 & \\
$\mathrm{KCl}(\mathrm{mmol} / \mathrm{L})$ & 2.7 & 18.8 & 38.8 & 15 \\
$\mathrm{Na}_{2} \mathrm{HPO}_{4}(\mathrm{mmol} / \mathrm{L})$ & 8.1 & 8.1 & 8.1 & \\
$\mathrm{KH}_{2} \mathrm{PO}_{4}(\mathrm{mmol} / \mathrm{L})$ & 1.2 & 1.2 & 1.2 & 15 \\
$\mathrm{~K}_{2} \mathrm{HPO}_{4}(\mathrm{mmol} / \mathrm{L})$ & & & & 42.5 \\
$\mathrm{NaHCO}_{3}(\mathrm{mmol} / \mathrm{L})$ & & & & 10 \\
$\mathrm{Glucose}(\mathrm{mmol} / \mathrm{L})$ & & & & 139 \\
Total $\mathrm{K}^{+}(\mathrm{mmol} / \mathrm{L})$ & 3.9 & 20 & 40 & 115 \\
Total Na & & & & \\
$\mathrm{pH}$ & 154 & 140 & 120 & 10 \\
Osmolarity $(\mathrm{mOsm})$ & 282 & 286 & 286 & 306 \\
\hline
\end{tabular}

experiments conformed to the U.S. National Institutes of Health, New England Deaconess Hospital, and Harvard Medical School regulations for animal care and use of laboratory animals. Unless otherwise stated, all reagents were purchased from Sigma Chemical Company (St. Louis, Mo).

Experimental procedures and protocol. The procedure for harvesting rat lungs was previously described. ${ }^{13}$ After cannulation of the pulmonary artery, the lungs were initially flushed in situ with cold $\left(4^{\circ} \mathrm{C}\right)$ flushing solution, $100 \mathrm{ml} / \mathrm{kg}$ body weight, from a height of $30 \mathrm{~cm}$. Excised lungs $(n=39)$ were divided into the following six groups according to the type of initial flushing solution: group 1 $(n=6)$, the UWS $\left(\mathrm{K}^{+}=140 \mathrm{mmol} / \mathrm{L}\right)$; group $2(n=6)$ : modified (low-potassium) UWS (mUWS; $\mathrm{K}^{+}=20 \mathrm{mmol} /$ $\mathrm{L})$; group $3(n=7)$, Dulbecco's phosphate-buffered saline solution (DPBS; $\left.\mathrm{K}^{+}=3.9 \mathrm{mmol} / \mathrm{L}\right)$; group $4(\mathrm{n}=7)$, modified (low potassium) PBS (mPBS1; $\mathrm{K}^{+}=20 \mathrm{mmol} /$ L); group $5(n=7)$, modified (high potassium) PBS $\left(\mathrm{mPBS} 2 ; \mathrm{K}^{+}=40 \mathrm{mmol} / \mathrm{L}\right)$; group $6(n=6), \operatorname{ECS}\left(\mathrm{K}^{+}=\right.$ $115 \mathrm{mmol} / \mathrm{L})$. These solutions were selected from the representative crystalloid or colloidal solutions with different potassium concentrations. The composition of each solution is shown in Tables I and II. The initial flushing was followed by a secondary flushing with cold storage solution (UWS, $50 \mathrm{ml} / \mathrm{kg}$ ) to prevent the initial flushing solution from remaining in the lung during the storage period. The lungs and heart were then harvested en bloc and stored, half-inflated with room air, for 24 hours at $4^{\circ} \mathrm{C}$. All lungs were stored in UWS. The experimental protocol for flushing and storage is summarized in Table III.

After storage for 24 hours in the UWS, all lungs were reperfused with fresh homologous venous blood exsanguinated from donor rats to allow for the evaluation of lung function by means of the previously described isolated, pulsatile, blood-perfused working lung model. ${ }^{13}$ Total pulmonary vascular resistance (in millimeters of mercury per millimeter per minute) was calculated and assessed. Vascular resistance was calculated both during flushing and during the perfusion period. Lung airway resistance (centimeters of water per milliliter per second) and dynamic lung compliance (milliliters per centimeter of wa- 


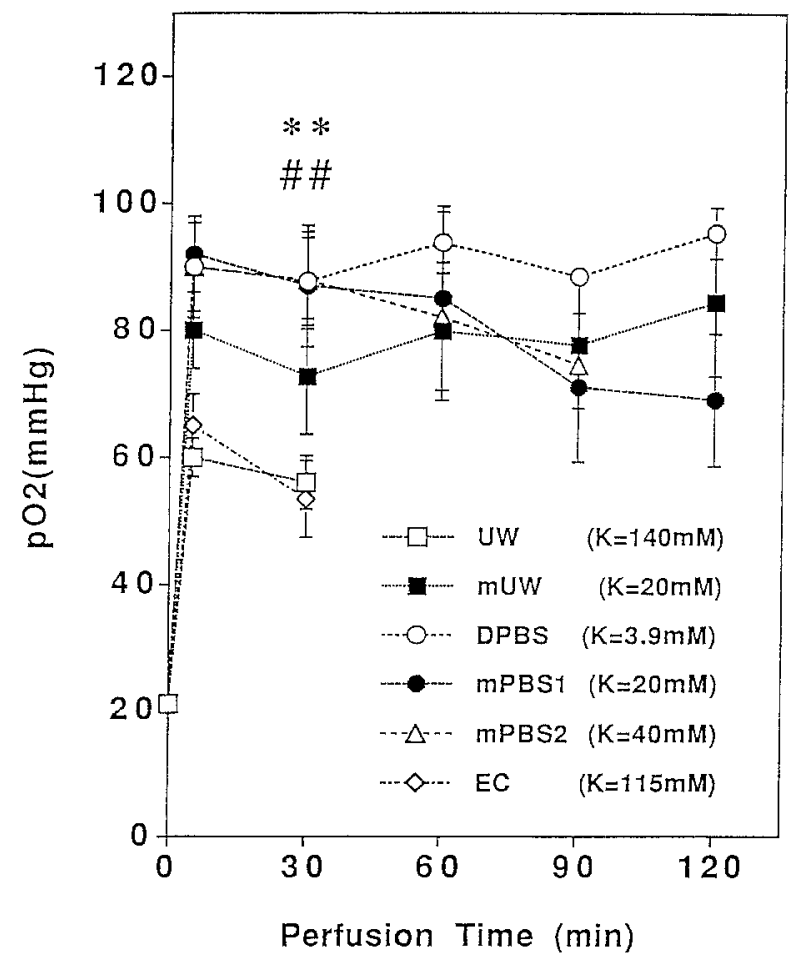

Fig. 1. Changes in oxygen tension $\left(\mathrm{PO}_{2}\right)$ during the reperfusion period. ** $p<0.01$ versus UWS; ${ }^{\# \#} p<0.01$ versus ECS.

ter) were calculated from the airway volume-pressure loop. ${ }^{14}$ Shunt fraction (percent) was calculated by the results of blood gas analysis. ${ }^{15}$ The lungs were perfused for 2 hours or until lung failure occurred. The perfusion time (up to 2 hours) was recorded as lung survival time.

Statistical analysis. All results were expressed as means \pm standard error of the mean, and differences were considered significant at the $p<0.05$ level. Data from all groups were compared by one-way analysis of variance with post hoc pairwise comparisons (Tukey-Kramer).

\section{Results}

Vascular resistance during flushing. Vascular resistance during flushing was used to reflect the degree of vasoconstriction during flushing. Vascular resistance (millimeters of mercury per milliliter per minute) for the various flushing solutions was as follows: UWS, $0.86 \pm 0.07$; mUWS, $0.43 \pm 0.02(p<$ 0.01 versus UWS); DPBS, $0.18 \pm 0.02(p<0.01$ versus UWS; $p<0.01$ versus ECS); mPBS1, $0.21 \pm 0.04$ ( $p<$ 0.01 versus UWS; $p<0.01$ versus ECS); mPBS2, 0.25 $\pm 0.02(p<0.01$ versus UWS; $p<0.01$ versus ECS); ECS, $0.50 \pm 0.02(p<0.01$ versus UWS). Significantly higher vascular resistances were found with intracellular fluid type solutions, which indicates that highpotassium solutions were associated with vasoconstric-
Table III. Experimental protocol

\begin{tabular}{|c|c|c|}
\hline Group & Initial flushing solution & $\begin{array}{c}\text { Second } \\
\text { flushing and } \\
\text { storage } \\
\text { solution }\end{array}$ \\
\hline $\begin{array}{l}\text { Group } 1 \\
\quad(n=6)\end{array}$ & $\begin{array}{l}\text { UW (colloid, } \mathrm{K}^{+}= \\
140 \mathrm{mmol} / \mathrm{L})\end{array}$ & $\begin{array}{l}\text { UW, storage } \\
\text { for } 24 \mathrm{hr}\end{array}$ \\
\hline $\begin{array}{l}\text { Group } 2 \\
\quad(n=6)\end{array}$ & $\begin{array}{l}\mathrm{mUW}\left(\text { colloid, } \mathrm{K}^{+}=\right. \\
20 \mathrm{mmol} / \mathrm{L} \text { ) }\end{array}$ & $\begin{array}{c}\text { UW, storage } \\
\text { for } 24 \mathrm{hr}\end{array}$ \\
\hline $\begin{array}{l}\text { Group 3 } \\
\quad(n=7)\end{array}$ & $\begin{array}{l}\text { DPBS (crystalloid, } \mathrm{K}^{+}= \\
\quad 3.9 \mathrm{mmol} / \mathrm{L} \text { ) }\end{array}$ & $\begin{array}{l}\mathrm{UW} \text {, storage } \\
\text { for } 24 \mathrm{hr}\end{array}$ \\
\hline $\begin{array}{l}\text { Group } 4 \\
\quad(n=7)\end{array}$ & $\begin{array}{l}\mathrm{mPBS} 1 \text { (crystalloid, } \mathrm{K}^{+}= \\
20 \mathrm{mmol} / \mathrm{L} \text { ) }\end{array}$ & $\begin{array}{l}\text { UW, storage } \\
\text { for } 24 \mathrm{hr}\end{array}$ \\
\hline $\begin{array}{l}\text { Group } 5 \\
\quad(n=7)\end{array}$ & $\begin{array}{l}\text { mPBS2 (crystalloid, } \mathrm{K}^{+}= \\
\quad 40 \mathrm{mmol} / \mathrm{L} \text { ) }\end{array}$ & $\begin{array}{l}\text { UW, storage } \\
\text { for } 24 \mathrm{hr}\end{array}$ \\
\hline $\begin{array}{l}\text { Group } 6 \\
\quad(n=6)\end{array}$ & $\begin{array}{c}\text { EC (crystalloid, } \mathrm{K}^{+}= \\
115 \mathrm{mmol} / \mathrm{L})\end{array}$ & $\begin{array}{l}\mathrm{UW} \text {, storage } \\
\text { for } 24 \mathrm{hr}\end{array}$ \\
\hline
\end{tabular}

tion during flushing. Vascular resistance measured during reperfusion was not different between groups.

Lung survival time. Lung survival time is indicated as the time until lung failure or 2 hours of reperfusion. Mean lung survival time (minutes) for each group was as follows: UWS, $30.0 \pm 1.3$, mUWS, $110.0 \pm 10.0(p<0.01$ versus UW; $p<0.01$ versus EC); DPBS, $120.0 \pm 0.0(p<0.01$ versus $\mathrm{UW} ; p<0.01$ versus EC); mPBS1, $117.9 \pm 2.1(p<$ 0.01 versus $U W ; p<0.01$ versus EC); mPBS2, 92.1 \pm 13.3 ( $p<0.01$ versus $\mathrm{UW} ; p<0.01$ versus $\mathrm{EC}$ ); ECS, $34.2 \pm 11.7$. These data indicated that the lungs remained viable and maintained the ability for oxygenation for a longer period in the group flushed with low-potassium solution than with high-potassium solution. Lung survival times in $\operatorname{mPBS} 2\left(\mathrm{~K}^{+}=\right.$ $40 \mathrm{mmol} / \mathrm{L}$ ) were significantly lower than those in groups flushed with solutions containing a 20 $\mathrm{mmol} / \mathrm{L}$ concentration of potassium or less (DPBS; $\left.\mathrm{K}^{+}=3.9 \mathrm{mmol} / \mathrm{L}\right)(p<0.05)$.

Blood gas analysis and shunt fraction. The partial pressure of oxygen is currently regarded as the most important parameter in allowing for the assessment of lung graft function. ${ }^{16}$ Fig. 1 shows the oxygen tension during reperfusion after storage. Mean values for the DPBS, mPBS1, and mPBS2 groups were significantly higher than for either the ECS or UWS groups $(p<0.01)$. Values for mean oxygen tensions were maintained within physiologic ranges during the perfusion period. The values for shunt fraction indicated a similar trend to those of oxygen tension. Shunt fractions at 30 minutes after the onset of reperfusion for UWS, mUWS, DPBS, mPBS1, mPBS2, and ECS groups were $40.6 \% \pm$ $8.3 \%, 16.4 \% \pm 4.9 \%(p<0.05$ versus UWS; $p<$ 


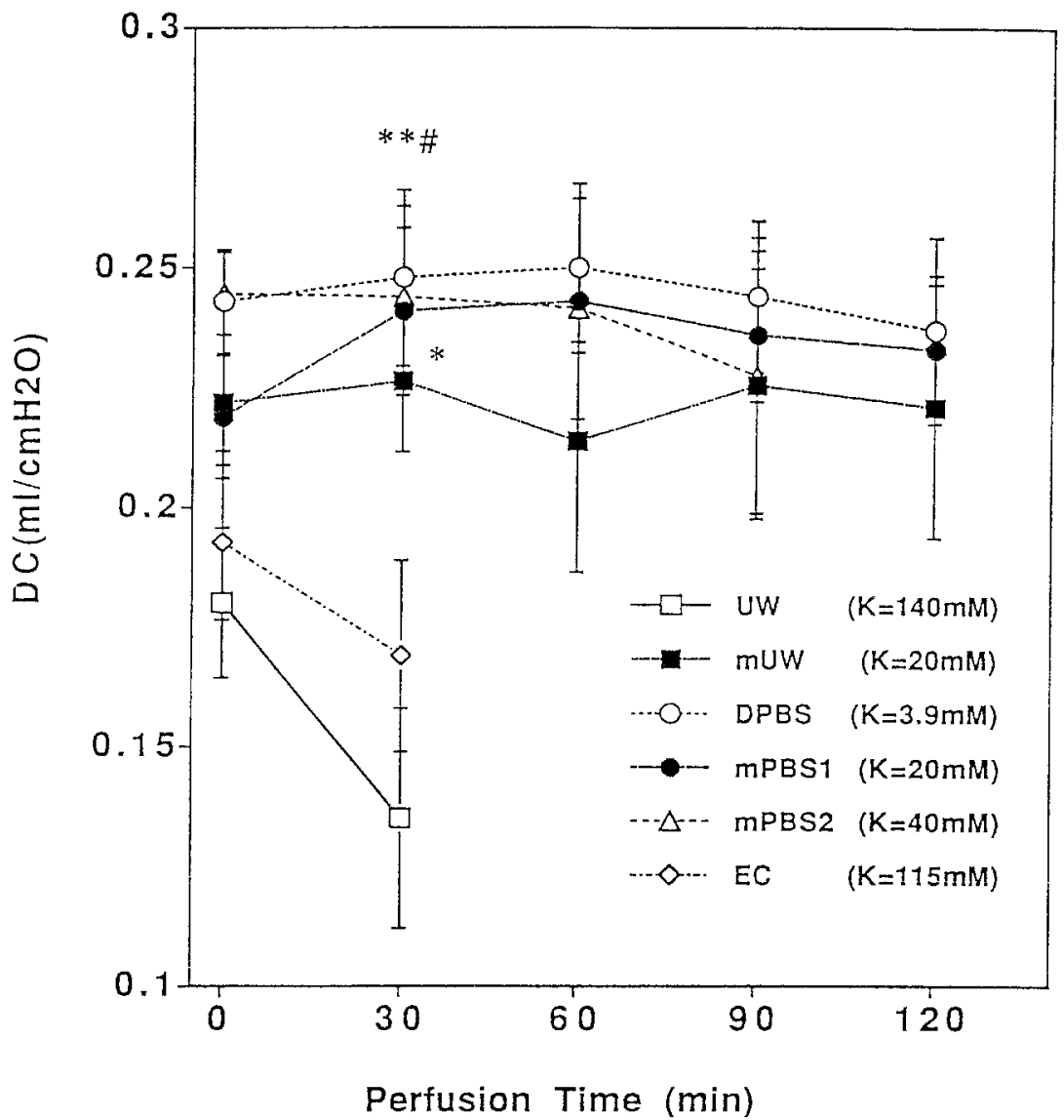

Fig. 2. Changes of the dynamic compliance $(D C)$ during the reperfusion period. ${ }^{*} p<0.05 ;{ }^{* *} p<0.01$ versus UWS, ${ }^{\#} p<0.05 ;{ }^{\# \#} p<0.01$ versus ECS.

0.05 versus $\mathrm{ECS}), 12.8 \% \pm 2.4 \%(p<0.05$ versus UWS; $p<0.05$ versus ECS), $12.0 \% \pm 2.2 \%$ ( $p<$ 0.05 versus UWS; $p<0.05$ versus ECS), $20.7 \% \pm$ $7.2 \%$, and $36.8 \% \pm 8.7 \%$, respectively. Values remained stable for 2 hours except in the UWS and ECS groups, in which values deteriorated within 30 minutes of perfusion.

Lung airway resistance and dynamic lung compliance. Values for the lung airway resistance (centimeters of water per milliliter per second) at the onset of reperfusion for UWS, mUWS, DPBS, mPBS1, mPBS2, and ECS groups were $4.25 \pm 0.43$, $2.85 \pm 0.12(p<0.01$ versus UWS; $p<0.05), 3.11 \pm$ 0.12 ( $p<0.01$ versus UWS $), 3.08 \pm 0.21(p<0.01$ versus UWS $), 3.23 \pm 0.13(p<0.05)$, and $3.62 \pm$ 0.14 , and those values at 30 minutes of perfusion were $5.76 \pm 0.93,2.82 \pm 0.16(p<0.01$ versus UWS; $p<0.05), 3.06 \pm 0.17(p<0.01$ versus UWS; $p<$ 0.05 ), $2.78 \pm 0.16$ ( $p<0.01$ versus UWS; $p<0.01$ versus ECS), $3.68 \pm 0.32(p<0.05)$, and $4.95 \pm$ 0.52 , respectively. Values for the mUWS, DPBS, and mPBS1 groups were significantly better than those for either the UWS or ECS groups and remained stable during 2 hours of the perfusion period. Fig. 2 shows changes of the dynamic lung compliance (milliliters per centimeter of water). Dynamic lung compliance remained stable for 2 hours in the groups flushed with low-potassium perfusate but deteriorated within 30 minutes in the UWS and ECS groups.

\section{Discussion}

The ultimate composition of lung preservation solutions remains controversial. The current standard solution for lung preservation is still ECS, ${ }^{1}$ which has the electrolyte composition of an intracellular type solution, containing high potassium and low sodium concentrations. The UWS, which has recently demonstrated better results on lung preservation, ${ }^{17-19}$ is also an intracellular fluid type solution. In standard procedures of lung preservation, prostaglandin $\mathrm{E}_{1}(500 \mu \mathrm{g})$ is usually given by 
direct injection into the pulmonary artery before flushing to produce pulmonary vasodilation and to enhance distribution of the flush solution, because solutions with high potassium concentrations have been shown to cause vasoconstriction. ${ }^{1,3,4}$

Keshavjee and associates ${ }^{5,7}$ recently demonstrated the superiority of low-potassium dextran solution and low-potassium UWS, extracellular fluid type solutions, on lung preservation. They have also demonstrated that prostaglandin $E_{1}$ does not enhance the effect of low-potassium dextran solution on lung preservation. ${ }^{20}$ These studies evaluated lung function after preservation with the use of the same solution for both flushing and storage and did not investigate separately the effect of each solution for flushing and for storage. Therefore, the question remains as to the benefits of the extracellular fluid type solution versus intracellular fluid type solution both for flushing and for storage. In this study, we used UWS for storage for two reasons. First, UWS is a standard solution in current clinical use for lung preservation. Second, we wished to eliminate the species difference of xanthine oxidase activity between human beings and rats. UWS contains allopurinol, which inhibits the high activity of xanthine oxidase in rat species.

Our results demonstrate that flushing with an extracellular fluid type solution is superior to flushing with an intracellular fluid type solution regardless of colloid or crystalloid type when lung function is compared after 24 hours of storage in UWS. Moreover, our data demonstrate that initial flushing is essential for successful lung preservation. In addition, we have shown that the potassium concentration in the flushing solution should be $20 \mathrm{mmol} / \mathrm{L}$ or less. This potassium concentration is consistent with the threshold values that have been shown to induce vasoconstriction in the rat pulmonary artery. $^{3}$

It must be acknowledged that rodent lungs are very sensitive to potassium concentration changes as demonstrated by this current study, as well as by those performed on rabbits by Yamazaki and associates. ${ }^{9}$ Pulmonary resistance in rodents and other animals can be modified by methods other than manipulating the potassium concentration, such as pretreatment with prostaglandin $\mathrm{E}_{1}$ or lung hyperinflation. ${ }^{10} \mathrm{It}$ is possible but not proven that the less sensitive human lungs may be adequately perfused if these methods are used. In fact, preliminary investigations in our laboratory suggest that the effect of prostaglandin $E_{1}$ is transient, with its action as short as 20 to 30 seconds, which may or may not be sufficient time for instillation of the preservation solution. Certainly, low initial potassium concentrations, even in rodents, will eliminate the concern about adequate solution delivery.

The present study demonstrates that extracellular fluid type solutions are superior to intracellular fluid type solutions, at least for flushing. The question of which solution is best for lung storage remains unresolved. In general, intracellular fluid type solutions have been considered more beneficial for organ storage than extracellular fluid type solutions, ${ }^{21}$ because the electrolyte composition (high potassium and low sodium) would not involve the $\mathrm{Na}^{+}, \mathrm{K}^{+}$exchange pump and therefore not require the cellular membrane to consume adenosine triphosphate.

In addition, this composition would prevent $\mathrm{Na}^{+}$ influx into the cell and prevent cell swelling. Intracellular fluid type solutions may, however, have the disadvantage of calcium regulation. Calculated membrane potential is nearly $0 \mathrm{mV}$ under conditions in which the potassium concentration of intracellular and extracellular fluid is almost the same (Nernst equation). Cellular membranes are completely depolarized under these conditions, which would result in calcium accumulation through the opening of the voltage-dependent calcium channels during storage with intracellular fluid type solutions. ${ }^{11,22-25}$ Most preservation solutions, such as ECS, UWS, and low-potassium dextran solution, are calcium-free solutions. We speculate that extracellular calcium would remain in the lung tissue because it could not be depleted by initial flushing. Calcium could also be released from sarcoplasmic reticulum, which is tightly linked with the plasma membrane in vascular smooth muscle cells. Another disadvantage is that the intracellular fluid type solution would enhance calcium overload at the time of reperfusion by opening the voltage-dependent calcium channels because of depolarization and would enhance reperfusion injury. ${ }^{11,25}$

In conclusion, we have demonstrated that an extracellular fluid type solution was better than an intracellular fluid type solution, at least for flushing the lung followed by storage with the UWS. Lung flushing using extracellular fluid type solution provided excellent lung function after storage for 24 hours. Although prostaglandin $\mathrm{E}_{1}$ or hyperinflation may improve flow, keeping the potassium concentration in the flushing solution at $20 \mathrm{mmol} / \mathrm{L}$ or less assures appropriate flushing and adequate distribu- 
tion of storage solution. It is still uncertain whether an extracellular fluid type solution is more beneficial than an intracellular fluid type solution for storage; however, we recommend that future studies should uniformly use a low-potassium extracellular fluid type solution for lung flushing as the standard method when the effects of storage solutions are being compared.

\section{REFERENCES}

1. Kaiser L, Cooper J. The current status of lung transplantation. Adv Surg 1992;25:259-307.

2. Novick R, Menkis A, McKenzie F. New trends in lung preservation: a collective review. J Heart Lung Transplant 1992;11:377-92.

3. Ryman T, Brandt L, Anderson KE, Mellergard P. Regional and species differences in vascular reactivity to extracellular potassium. Acta Physiol Scand 1989; 136:151-9.

4. Kimblad P, Sjoberg T, Massa G, Solem J, Steen S. High potassium contents in organ preservation solutions cause strong pulmonary vasocontraction. Ann Thorac Surg 1991;52:523-8.

5. Keshavjee SH, Yamazaki F, Yokomise H, et al. The role of dextran 40 and potassium in extended hypothermic lung preservation for transplantation. J THORaC Cardiovasc Surg 1992;103:314-25.

6. Oka T, Puskas JD, Mayer E, et al. Low-potassium UW solution for lung preservation. Transplantation 1991;52:984-8.

7. Keshavjee SH, McRitchie DI, Vittorini T, Rotstein OD, Slutsky AS, Patterson GA. Improved lung preservation with dextran 40 is not mediated by a superoxide radical scavenging mechanism. J THORAC CARDIOVASC SURG 1992;103:326-8.

8. Maccherini M, Keshavjee SH, Slutsky AS, Patterson GA, Edelson JD. The effect of low-potassium-dextran versus Euro-Collins solution for preservation of isolated type II pneumocytes. Transplantation 1991;52: 621-6.

9. Yamazaki F, Yokomise H, Keshavjee SH, et al. The superiority of an extracellular fluid solution over Euro-Collins' solution for pulmonary preservation. Transplantation 1990;49:690-4.

10. Puskas JD, Cardoso PF, Mayer E, Shi S, Slutsky AS, Patterson GA. Equivalent eighteen-hour lung preservation with low-potassium dextran or Euro-Collins solution after prostaglandin $E_{1}$ infusion. J THORAC CARDIOVASC SURG 1992;104:83-9.

11. Kilgore K, Lucchesi B. Reperfusion injury after myocardial infarction: the role of free radicals and the inflammatory response. Clin Biochem 1993;26:359-70.

12. McCord J. Human disease, free radicals, and the oxidant/antioxidant balance. Clin Biochem 1993;26: 351-7.
13. Sasaki S, McCully JD, LoCicero J. Development of an isolated blood-perfused working rat lung model. Surg Forum 1993;44:312-4.

14. Berne R, Levy M. Organization and mechanics of the respiratory system. In: Physiology. 2nd ed. St. Louis: Mosby, 1988:575-97.

15. Mountcastle V. Medical physiology. 14th ed. Vol 2. St. Louis: Mosby 1980:1715-7.

16. Miyoshi S, Shimokawa S, Schreinemakers H, et al. Comparison of the University of Wisconsin preservation solution and other crystalloid perfusates in a 30-hour rabbit lung preservation model. J THORAC CARDIOVASC SuRg 1992;103:27-32.

17. Bresticker M, LoCicero J, Oba J, Greene R. Successful extended lung preservation with UW solution. Transplantation 1992;54:780-4.

18. Kawahara K, Ikari H, Hisano H, et al. Twenty-fourhour canine lung preservation using UW solution. Transplantation 1991;51:584-7.

19. Kawahara K, Kobayashi S, Takahashi T, et al. Efficacy of University of Wisconsin solution for canine lung preservation. Transplant Proc 1993;25:1599-600.

20. Ueno T, Yokomise H, Oka T, et al. The effect of $\mathrm{PGE}_{1}$ and temperature on lung function following preservation. Transplantation 1991;52:626-30.

21. Belzer FO, Southard JH. Principles of solid-organ preservation by cold storage. Transplantation 1988; 45:673-6.

22. Johns A, Leijten P, Yamamoto H, Hwang K, Breemen C. Calcium regulation in vascular smooth muscle contractility. Am J Cardiol 1987;59:18A-23A.

23. Morgan K. Role of calcium ion in maintenance of vascular smooth muscle tone. Am J Cardiol 1987;59: 24A-8A.

24. Triggle DJ, Zheng W, Hawthorn M, et al. Calcium channels in smooth muscle: properties and regulation. Ann NY Acad Sci 1989;560:215-29.

25. Hurwitz L. Pharmacology of calcium channels and smooth muscle. Ann Rev Pharmacol Toxicol 1986;26: 225-58.

\section{Discussion}

Dr. Robert A. Guyton (Atlanta, Ga.). When you change the potassium solution you are taking out $80 \mathrm{mEq}$ of potassium. What cation are you replacing this with, or does the osmolarity of the solution remain the same? What is the composition of the low-potassium UWS? Do you add sodium to make up for the absence of potassium?

Dr. Sasaki. PBS and mPBS have the same osmolarity of about 290 mOsm. UWS and the modified UWS, both of which are colloidal solutions, have the same osmolarity of $320 \mathrm{mOsm}$. Potassium was replaced with sodium to maintain the same osmolarity.

Mr. Nicholas Odom (Manchester, England). We have done some similar experiments and we found totally different results. We found that the high potassium concentration worked well and the high sodium concentration did not work at all. 
However, when we changed the conditions of perfusion during the first few minutes and reduced the flow and the pressure, we got entirely different results. We were unable to demonstrate any significant difference.

Can you be a little more precise about the conditions of flow and pressure with which you were perfusing these lungs, particularly during the first 10 to 15 minutes of reperfusion? During that time you get marked changes in pulmonary vascular resistance, particularly in the lungs stored in high-potassium solutions.

Dr. Sasaki. Perfusion commenced at a flow of 0.03 $\mathrm{ml} / \mathrm{gm}$ body weight per minute and was gradually increased to a final flow of $0.1 \mathrm{ml} / \mathrm{gm}$ body weight per minute with increments of $0.02 \mathrm{ml} / \mathrm{gm}$ body weight per minute every 5 minutes. The increase in pulmonary vascular resistance at the onset of reperfusion may result from the high-potassium storage solution, as you mentioned. In addition, calcium may enter not only from the voltage-dependent calcium channels but also from the site of damaged membrane after storage.

Dr. Shaf Keshavjee (Toronto, Ontario, Canada). Your first slide indicated that there was no evidence for improved storage with the low-potassium dextran solution. We have been studying that for several years in Toronto. We initially showed that it had improved preservation over ECS. We went on to study the role of potassium in that solution by varying the concentrations of potassium in low-potassium dextran solution without changing anything else. We confirmed that the high potassium concentration was indeed causing the problem and that a low potassium concentration was better.

In work done by Fumio Yamasaki, who was a fellow in our laboratory at the same time, we studied the issue of the storage versus the flush phase of preservation. We showed that storage in the high-potassium solution was deleterious even if storage was preceded by a flush with a low-potassium solution initially, whereas storage in lowpotassium dextran solution produced superior results.

Furthermore, we studied the same issue using isolated type II pneumocytes in culture and showed that cells stored in the low-potassium dextran solution at $5^{\circ} \mathrm{C}$ had improved viability.

Do you have any evidence at all to recommend UWS as a storage solution for lung preservation even after a low-potassium flush?

Dr. Sasaki. We used UWS in this study because it is one of the standard solutions for lung preservation and because it contains allopurinol, which may reduce a high activity of the xanthine oxidase in rats. We compared and discussed only the effect of flushing solution on lung function after storage. Comparisons between the efficacy of high-potassium solution and low-potassium solution for storage require another study.

Dr. Frederick L. Grover (Denver, Colo.) Clinically we give prostaglandin $\mathrm{E}_{1}$ before flushing the lungs. Have you looked to see whether pre-administration of prostaglandin $\mathrm{E}_{1}$ would affect these results?

Dr. Sasaki. We did not use prostaglandin $E_{1}$ in this study, because we would like to determine the precise effects of potassium concentration in flushing solutions influencing lung function after storage. We have examined vasodilatory effects of prostaglandin $\mathrm{E}_{1}$ on high-potassium solutions in another study. We have observed that voltagedependent calcium channel blockers were more beneficial than prostaglandin $\mathrm{E}_{1}$ for attenuating vasoconstriction by high-potassium solutions. 